\title{
Relações entre o Brasil e a África subsaárica
}

\section{JOSÉ VICENTE DE SÁ PIMENTEL*}

O Chanceler Luiz Felipe Lampreia tem reiterado que a África é um objetivo insubstituível da política externa brasileira. Elemento essencial na formação econômica e na construção da identidade nacional, as relações com o continente africano são responsáveis por páginas expressivas da história de nossa diplomacia e configuram ponto de apoio estratégico da inserção internacional do Brasil.

No entanto, quando conferimos o quadro do relacionamento atual, não escapamos da constatação de que dificuldades existem. Diagnosticar suas causas e definir meios e modos de superá-las é um exercício permanente da diplomacia. As conjunturas brasileira, africana e internacional criam continuamente novas oportunidades e desafios, que uma política externa conseqüente não pode ignorar.

A rigor, dificuldades existirão sempre nas relações com qualquer país e qualquer região. Ao repercutirem internamente, geram, entre outras, reações de setores técnicos, que apresentam alternativas de ação, ou políticos, que cobram atitudes do Governo. Ocorre, contudo, que os temas africanos têm entre nós uma trajetória peculiar. Suas repercussões são episódicas e emocionais. Talvez por isso, as percepções mais difundidas sobre as relações do Brasil com o continente africano em geral oscilam entre dois pólos extremados, um decididamente nostálgico, outro catastrófico.

\section{Nostálgicos e catastrofistas}

Os nostálgicos costumam sublinhar as nossas responsabilidades históricas e se queixam de que já não há uma política africana com brilho e ousadia comparáveis à dos anos 70. Proclamam que o Governo tem obrigação de fazer mais, em decorrência de nossa dívida irresgatável para com a África.

Os catastrofistas brandem estatísticas e vociferam que o Brasil não tem mais nada a fazer com os africanos. Salientam que no espaço de 40 anos a África subsaariana foi palco de dezenas de conflitos, causadores de 10 milhões de mortos e 20 milhões de refugiados; a mortalidade infantil africana é 11 vezes superior à 
européia e a expectativa de vida abaixo dos 50 anos; 71\% dos infectados pela AIDS no mundo estão na África, onde também se originou o ebola; o Banco Mundial já estimou que, ao ritmo do início dos anos 90, serão necessários 40 anos para que a África negra recupere o nível dos anos 70; o mesmo BIRD avalia que, de 1989 até 1995, foram gastos na África aproximadamente US\$ 4,5 bilhões em armas, enquanto que para educação e saúde foram canalizados apenas US\$1,8 bilhão; segundo o World Resources Institute, dois em cada cinco cidadãos africanos atuam diretamente em conflitos militares ou interétnicos; $60 \%$ dos combatentes têm entre 13 e 18 anos; o número de mutilados é de quase 4 milhões de pessoas; muitos países são governados por regimes militares e vários estão em guerra civil em maior ou menor escala e/ou têm grupos guerrilheiros ativos.

Os números são impressionantes, mas o que distingue, de fato, os catastrofistas é a descrença em que os africanos possam reverter esse quadro. Há gradações de racismo indisfarçáveis em seu pretenso realismo.

Nenhum desses pólos examina a situação em sua inteireza. Aos nostálgicos, conviria lembrar que também nos anos 70 a política externa pretendia expandir laços concretos, e a possibilidade de levá-la adiante fundamentava-se na capacidade de ação governamental e de projeção da economia brasileira, como demonstra Gelson Fonseca Jr. A crise do petróleo tornou estratégico o relacionamento com produtores como Argélia e Nigéria, e a prioridade então atribuída à promoção de exportações e à ampliação de mercados justificava tentativas, impulsionadas por financiamentos de um Estado que se considerava onipresente indutor do desenvolvimento, de implantação de empresas brasileiras em países africanos. Em retrospecto, verificamos que nem todos os esforços dos anos 70 foram bem sucedidos; a dívida remanescente, que dificilmente será remida por vários devedores, sinaliza a necessidade de prudência em novos empreendimentos. Paralelamente, o fim do bipolarismo, a prevalência das noções de mercado e a virtual eliminação do conceito de desenvolvimento da pauta internacional alteraram substancialmente as possibilidades de ação solidária. Por sua vez, na África, as perspectivas otimistas de três décadas atrás definharam, as lideranças não se renovaram e, sem a muleta ideológica, perderam expressão, as economias, em grande número, involuíram e os Estados se debilitaram.

É curiosa a insistência em uma política africana, que pareceria sugerir uma repartição eqüânime dos meios da diplomacia brasileira entre parceiros tão díspares como Angola e Burquina-Fasso, África do Sul e Ruanda, Nigéria e Djibuti. Ora, com a mesma naturalidade com que se admite que Alemanha, Luxemburgo, França e Portugal oferecem oportunidades específicas, que demandam respostas individualizadas, não necessariamente generalizáveis sob o rótulo de "política européia”, também na África cumpre aplicar os nossos recursos com critério. Seletividade não significa desinteresse pelas grandes causas comuns a todos os africanos - de resto, a toda a humanidade - como a busca da paz, o desenvolvimento 
econômico, a democracia, os direitos humanos. Denota, apenas, pragmatismo na alocação de recursos limitados.

As teses catastrofistas parecem ainda mais deslocadas da realidade. Em seu imediatismo, desvalorizam as oportunidades abertas pela qualidade do nosso trânsito diplomático com os países africanos e descuram do fato de que vários deles vêm obtendo, desde 1994, taxas anuais de desenvolvimento econômico superiores a $5 \%$, com alguns desempenhos individuais destacados, acima de $10 \%$. Incentivar essa tendência é do interesse de toda a comunidade internacional, pois, de um lado, o crescimento africano redundaria em lucros também extrazonais e, do outro, os custos sócio-econômicos de uma regressão caótica do continente africano seriam imensos e não se limitariam à África. Basta imaginar os agravos à consciência e a intranqüilidade política que fortes surtos migratórios de africanos flagelados provocariam nos países de destino.

\section{A crise africana}

Para entender a crise africana em toda a sua complexidade, convém investigar-lhe as causas. Christopher Clapham propõe a tese de que a era póscolonial somente agora está terminando na África. Lançados à independência há cerca de 40 anos, com fronteiras desenhadas de forma quase randômica, desatentas das zonas ecológicas e dos padrões sociais autóctones, em geral desprovidos de coerência interna e carentes de infra-estrutura, os Estados subsaáricos eram candidatos improváveis à sobrevivência. Em retrospecto, muitos deles fizeram até mais do que se poderia esperar. As estruturas políticas formais deixadas pelos colonizadores, impraticáveis, na maioria dos casos, dadas as condições nativas, foram absorvidas pelo que Patrick Chabal denominou de "sistema neopatrimonial”, sob cuja égide as elites locais se asseguraram de certos privilégios e em troca admitiram a autoridade do Estado.

A Organização da Unidade Africana priorizou, hobbesianamente, o reforço da soberania dos Estados membros e a regulamentação das relações entre eles. As superpotências, a princípio sem maiores interesses na África, deixaram às antigas metrópoles a transmutação das colônias em Estados. O ambiente internacional permaneceu razoavelmente seguro para os novos países africanos nas duas décadas subseqüentes à independência.

Na virada dos anos 70, porém, o neopatrimonialismo entrou em colapso e os dirigentes africanos pretenderam compensar pela força o que não mais conseguiam pela persuasão. A doutrina da soberania irrestrita, de início conveniente para a consolidação dos frágeis Estados, gerou um mecanismo pernicioso, que estimulava regimes autocráticos a recorrerem à ajuda militar dos seus patrocinadores internacionais, ao invés de negociarem soluções endógenas. A resistência interna intensificava os temores das metrópoles, potencializados pela lógica da Guerra 
Fria. Assim, estavam dadas as condições para uma intensa militarização do continente.

A partir dos anos oitenta, instituições financeiras internacionais, lideradas pelo FMI e pelo Banco Mundial, impuseram os programas de ajustamento estrutural, que os Estados africanos absorveram, seja pela fragilização decorrente do endividamento externo, seja pelo hábito de recorrer ao receituário ocidental. Enquanto o ajustamento estrutural pretendia criar as condições para que o livre mercado sanasse a incompetência e saneasse a corrupção, as ONGs supunhamse capazes de suplementar ou substituir os governos africanos em quase todos os setores de atividade, as ênfases episódicas ziguezagueando do combate à desnutrição à proteção de elefantes e rinocerontes. Nas brechas deixadas pelo declínio do comunismo, procurava-se complementar a reforma econômica com o liberalismo político.

Essa tentativa de reconstruir a África a partir da premissa simplista, mesmo se bem intencionada, de que todas as sociedades seguiriam o mesmo padrão de transformação econômica e sócio-cultural não vem tendo sucesso. Uma década e meia de ajustes estruturais não produziram sinais de transformação econômica, nem de estabilidade política na África.

Clapham sugere dois motivos básicos para o fracasso. Em primeiro lugar, o ajustamento estrutural embutia condicionalidades complexas, de delicado monitoramento, que dificilmente poderiam ser implementadas pelos governos que estavam sendo "aperfeiçoados". Em segundo lugar, foram sempre insuficientes os recursos que os países ocidentais se dispuseram a consignar, decorrência do baixo nível de prioridade política dos projetos. Os países ocidentais não estavam dispostos a se empenhar a fundo em áreas de interesse marginal.

\section{Ênfases diplomáticas brasileiras}

No Brasil, a década dos 80 também foi de crise, da qual emergiu a consciência da necessidade de atualizar a inserção mundial do país. Os anos 90, além das mudanças no mundo, trouxeram a consolidação político-institucional, a ênfase nos direitos humanos, o redimensionamento do Estado e a abertura econômica, evolução necessária para adequar o país aos anseios de seus eleitores e às conveniências do cenário internacional. No Governo Fernando Henrique Cardoso, as relações com Estados Unidos e Europa atingem níveis qualitativos excepcionais e, enquanto se avança em direção ao aprimoramento das relações com a Ásia, o sucesso do Mercosul faz as atenções do empresariado convergirem para os vizinhos continentais. Nesse contexto, a posição relativa da África perde atrativos.

A política externa não se detém, contudo, no curto prazo. A diplomacia brasileira reconhece o potencial africano e, por isso, empenha-se, no âmbito externo, 
para alavancar apoio às causas africanas e, no interno, para persuadir setores influentes da sociedade brasileira a se engajarem na ampliação do relacionamento com a África. Nesta última tarefa, os interesses econômico-comerciais assumem relevância fundamental. Ao falar nas perspectivas das relações Brasil-África, impõe-se conferir, portanto, uma atenção muito especial às oportunidades e desafios da vertente comercial do relacionamento.

\section{As relações comerciais}

Nesse exercício, há que distinguir os problemas genéricos, enfrentados por empresas de todos os países, daqueles específicos das empresas brasileiras em seu esforço para concorrer com as estrangeiras, sobretudo européias, já há muito estabelecidas abaixo do Saara.

Os primeiros vinculam-se à recorrente instabilidade política e econômica da maioria dos países africanos e são de molde a produzir dificuldades para a instalação e operação das empresas no terreno. Dizem respeito, essencialmente, ao "custo África".

O economista nigeriano Adebaio Adedeji sustenta que "a crise africana atual, embora com conseqüências econômicas devastadoras, é essencialmente política”. O tribalismo latente, o mau funcionamento das instituições do Estado e a falta de mecanismos políticos capazes de acomodar pacificamente os diversos interesses em conflito encontram-se no cerne da instabilidade nos países africanos.

A instabilidade gera um ambiente econômico de reduzida previsibilidade que, junto com as deficiências em infra-estrutura e com o baixo poder aquisitivo dos mercados africanos, desencoraja investimentos. Daí o "custo África” - montante extra de investimento requerido para superar deficiências estruturais, como falta de segurança; precariedade dos sistemas financeiro, de saúde, de transportes e de comunicações; baixa produtividade dos recursos humanos locais e elevados níveis de corrupção. O “custo África” erode o interesse pelo continente, afastando os países africanos das rotas dos capitais privados na atual fase de globalização da economia.

Estatísticas do Banco Mundial indicam que os fluxos financeiros líquidos para os 47 países da África subsaárica apresentaram uma queda real de 16,9\% entre 1980 e 1993. Em 1995, a região captou menos de 3\% dos investimentos estrangeiros diretos realizados em países em desenvolvimento e participou com apenas $1,4 \%$ do total das exportações mundiais.

Soma-se a isso a crise dos organismos financeiros multilaterais que foram peça chave do crescimento econômico africano nos anos 70. A ajuda externa vem sendo considerada pelos próprios governos africanos como uma dying industry, incapaz de reagir diante das necessidades de investimento naquele continente. Enquanto os capitais privados aumentaram em US\$ 60 bilhões no biênio 1995- 
1996, a assistência oficial ao desenvolvimento, provinda de instituições multilaterais, caiu em cerca de US\$ 12 bilhões. Ora, na África subsaárica a ajuda oficial era responsável, em 1993, por 91\% dos fluxos líquidos totais.

A partir dos anos 80, começou a ser questionada a utilização de recursos multilaterais para financiar investimentos estatais em modelos de desenvolvimento centrados na substituição de importações e na proteção ao mercado interno. Essa tendência vem ditando um comportamento crescentemente austero por parte dos países doadores. Em conseqüência, os investimentos brutos nos países africanos, vinculados basicamente a aportes das agências multilaterais, diminuíram 22\% entre 1980 e 1994, passando de $18,6 \%$ para $10,8 \%$ do PIB.

A queda das receitas das exportações tradicionais, determinada pela deterioração dos preços das commodities, gerou a acumulação de atrasados nos pagamentos da dívida externa, hoje uma variável crítica. Os países mais pobres altamente endividados (highly indebted poorer countries - HIPCs) encontramse predominantemente na África: dos 41 HIPCs, 33 são africanos e entre os 20 HIPCs para os quais a situação do endividamento foi avaliada como insustentável, 16 estão na África subsaárica. A realidade atual do continente, em particular a realidade dos HIPCs, combina dívidas crescentes e estagnação econômica, revelando que todos esses anos de políticas de ajustes estruturais não foram suficientes para dar partida ao crescimento sustentado na África.

Por sua vez, as dificuldades específicas do empresariado brasileiro estão ligadas a: questões subjetivas, como o desconhecimento mútuo e a preferência africana pelas empresas européias e seus produtos; escassez de transporte direto entre o Brasil e a África; práticas indevidas, como protecionismo, subsídios e reserva de mercados, em detrimento de empresas brasileiras; deficiências nos mecanismos de crédito e seguros para exportações de bens e serviços brasileiros.

Excluídas algumas grandes empresas, que procuram consolidar presença no continente, o setor privado brasileiro não está familiarizado com as diferenças entre os diversos países africanos, tendendo a julgar a África como um todo em função dos aspectos negativos ressaltados pela imprensa.

No sentido inverso, os africanos também desconhecem a qualidade de nossos serviços e produtos. As intensas ligações com a Europa e a longa tradição de produtos e empresas européias criaram vínculos quotidianos de informações que providenciam a atualização constante dos consumidores africanos. Por conseguinte, desenvolve-se de modo subliminar a confiança e a simpatia do africano por determinadas empresas e produtos europeus.

As empresas européias, implantadas há longo tempo nos países africanos, participam do mercado de bens e serviços com conhecimento do terreno semelhante ao de uma empresa local. Isto traz competitividade em termos de custos de instalação e mobilização. As empresas possuem equipamentos já alocados aos projetos do 
país, equipes com quadros africanos e conhecimento das exigências legais e do funcionamento da burocracia local.

Tais aspectos acabam por determinar, em uma relação ao mesmo tempo de causa e efeito, fluxos comerciais constantes com a Europa, os quais favorecem, por sua vez, o estabelecimento de rotas aéreas e de navegação, cuja existência influi positivamente nos custos. No caso brasileiro, ao contrário, a insuficiência de ligações diretas com o continente africano reduz a capacidade de concorrência em matéria de preço e prazo de transporte.

O protecionismo, os subsídios e as reservas de mercado são especialmente relevantes quando estão em jogo concorrências internacionais para obras de infraestrutura. Freqüentemente, os bancos de desenvolvimento de países europeus concedem financiamentos subsidiados aos países africanos com a contrapartida de que os projetos beneficiados sejam realizados por empresas dos países financiadores. Este é o caso, por exemplo, de instituições como FED (Fundo Europeu de Desenvolvimento), CED (Caisse Française de Dévélopement) e KFW (Fundo Alemão de Desenvolvimento). Além dos europeus, os fundos árabes, ao concederem financiamentos, normalmente exigem proteção para a empresa árabe ou islâmica que esteja participando da concorrência.

Outro complicador é a participação nas concorrências públicas de empresas estatais, notadamente de países socialistas ou ex-socialistas. Tais empresas beneficiam-se de subsídios dos respectivos Governos, provocando “dumping” nos preços e alijamento de empresas que não se valem dessa indevida proteção.

Em outros casos há, ainda, interferência direta de Governos, principalmente europeus, em favor de empresas de seus países, por meio de pressões políticas e "trade-offs" junto aos dirigentes africanos.

Finalmente, constata-se um desequilíbrio no tocante aos instrumentos de financiamento e seguro às exportações de bens e serviços. Alguns países europeus mantêm seguro de risco político, o que permite cobertura a empréstimos ou realizações em obras e serviços de suas empresas. Isto dá maior segurança às empresas européias, bem como aos seus fornecedores e sub-empreiteiros, no planejamento de suas propostas e na decisão sobre investimentos a serem feitos.

Apesar dos obstáculos, as estatísticas comerciais brasileiro-africanas dos últimos vinte e cinco anos apresentam quadro relativamente positivo. De 1970 a 1984, excetuadas breves descontinuidades nos períodos de 1975-77 e 1982-83, o comércio bilateral cresceu em níveis constantes, partindo de US\$ 130 milhões e superando os US\$ 3 bilhões. De 1985 a 1996, a despeito da crise econômica e da "década perdida", os fluxos comerciais anuais médios, nos dois sentidos, foram da ordem de US\$ 1,8 bilhão.

Em 1999, importamos da África um total de US\$ 2.222.163,30 e exportamos US\$1.336.446,20. Com relação a 1998, deu-se uma queda nas exportações da ordem de 19,1\%, devida principalmente a um acentuado declínio das vendas de 
açúcar, o que causou perdas de cerca de US\$ 147 milhões em receita. Por sua vez, o bloco africano aumentou suas vendas em $22,2 \%$, devido sobretudo às nossas aquisições de petróleo e derivados da Argélia e da Nigéria. O déficit de US\$ 885,7 milhões sugere a conveniência de iniciativas que compensem o aumento das importações com maiores compras de produtos brasileiros.

Esse objetivo é perfeitamente exeqüível. Dadas as afinidades culturais e a familiaridade estimulada por condições semelhantes de terreno e clima, as empresas brasileiras possuem vantagens comparativas para participar no desenvolvimento africano. O patamar tecnológico de nossas empresas permite atuação em setores de média complexidade, dotados de capacidade indutora, como a formação profissional, a construção civil, a agricultura, e outros.

Em seminário na FIRJAN, o Dr. Eduardo Eugênio Gouveia Vieira aventou a hipótese de o BNDES analisar a viabilidade da abertura de linhas de crédito para empresas brasileiras que fossem produzir na África. A sugestão mereceria uma avaliação generosa dos novos diretores do Banco.

A par disso, a experiência de integração entre economias de nível industrial médio, vivida no Mercosul, credencia o Brasil e seus parceiros sul-americanos a desenvolver uma cooperação com entidades de porte semelhante na África, gerando um efeito multiplicador sobre o relacionamento econômico-comercial.

\section{A parceria sul-africana}

Projeto dessa natureza está em gestação com a África do Sul. Em sua recente visita àquele país, o Ministro Luiz Felipe Lampreia levou minuta de acordo visando à efetiva integração das economias brasileira e sul-africana, a partir da liberalização do comércio recíproco. As negociações prevêem a participação dos nossos sócios no Mercosul, para evitar perfurações na tarifa externa comum.

A idéia é conduzir o tema em três etapas. De início, deverá ser assinado um acordo-quadro, que definirá cronogramas e critérios de negociação de um posterior acordo de preferências tarifárias fixas (nomenclatura, prazos de desgravação, disciplinas comerciais, outras matérias). Para o acordo de preferências tarifárias fixas, antecipa-se uma duração de cerca de dois anos. Um acordo de livre comércio culminaria o processo.

A gradual abertura dos mercados permitirá a identificação dos produtos a serem negociados, uma vez que o comércio Mercosul - África do Sul não tem ainda volume que permita antecipar com clareza as sensibilidades comerciais de lado a lado. Além disso, facilitará a aceitação do esquema pelas respectivas comunidades empresariais, que terão mais tempo para identificar seus interesses.

O intercâmbio comercial com a África do Sul ainda é modesto, em torno de meio bilhão de dólares nos dois sentidos. Representa pouco menos de $1 \%$ do comércio total sul-africano e algo em torno de 0,5\% do brasileiro. Em 1999, o 
Brasil obteve um superávit de US\$64 milhões, alterando o perfil do último qüinqüênio. A pauta do intercâmbio já é sofisticada, sendo os principais produtos, do lado das exportações brasileiras, veículos (21\%), caldeiras e máquinas (12\%) e aparelhos elétricos (6\%). Os novos acordos darão renovado ímpeto a essa tendência do relacionamento.

Há muitas outras áreas de expansão no relacionamento com a África do Sul, como os entendimentos diplomáticos sobre a reforma da ONU, o meio ambiente, a OMC pós-Seattle e o desarmamento nuclear, a cooperação cultural (as coproduções cinematográficas gerando expectativas atraentes) e técnica, científica e tecnológica, a colaboração nos setores da saúde (em especial na prevenção da AIDS) e militar, o combate ao narcotráfico. A agenda é farta, até porque os dois países se assemelham no que têm de bom e de mau. São nações multirraciais, democracias recentes, economias pujantes. São, também, sociedades injustas, que convivem com índices lamentáveis de distribuição de riqueza.

Desde 1994, com a eleição de Nelson Mandela, sobretudo desde 1996, ano da visita do Presidente Fernando Henrique Cardoso, o relacionamento vem assumindo ritmo acelerado. Recupera-se o tempo em que as relações governamentais ficaram reprimidas pela recusa brasileira a colaborar com o regime do apartheid. O Brasil deposita confiança nos dirigentes sul-africanos e discorda das previsões alarmistas que costumam surgir às vésperas de cada etapa da evolução institucional do país. A transição tranqüila da presidência de Mandela para a de Thabo Mbeki acrescenta razões para acreditar na competência das lideranças do Congresso Nacional Africano.

\section{A parceria angolana}

O Governo brasileiro está convencido de ter razão também no que diz respeito ao encaminhamento da questão angolana. Angola é um país rico. Dispõe de petróleo, diamantes e terras férteis, além de água, recurso de que carece a maioria dos países africanos. Fatores estruturais de aproximação são os vínculos históricos, a afinidade cultural e a singular contribuição angolana à formação do povo brasileiro.

Desde 1975, quando reconheceu o MPLA como o governo legítimo de Angola, o Brasil vem dando apoio a Luanda. Não se trata de uma aposta caprichosa, nem de uma opção inconseqüente. A decisão decorre de um diagnóstico ponderado, que leva em conta o fato de Angola ter sido uma das grandes vítimas da Guerra Fria e o MPLA a agremiação política local capacitada a manter a integridade do território angolano.

Além de enviar para Angola, no âmbito da UNAVEM, o maior contingente militar brasileiro no exterior desde a II Guerra Mundial, o Governo Fernando Henrique Cardoso Brasil vem multiplicando sinais de solidariedade, da qual um 
exemplo recente é a instalação, nas proximidades de Luanda, do Centro Móvel de Formação Profissional, com capacidade para formar centenas de profissionais de nível médio por ano. Em contrapartida, o Governo angolano retribui com impecável regularidade nos pagamentos da dívida externa e com acolhedora simpatia pelos produtos e empresas brasileiros. A Braspetro, que há anos atua no país, é candidata a novas licitações; dada a qualidade e amplitude dos serviços que vem prestando, inclusive na formação profissional de técnicos angolanos, não temos dúvida de que manterá a condição de âncora da cooperação bilateral. Por sua vez, a Odebrecht desenvolve projetos na hidrelétrica de Capanda, na mineração em Lusamba e Katoka e na construção de bairro residencial em Luanda. Várias outras de nossas empresas lá operam com ampla margem de sucesso.

No plano internacional, há muito o Brasil dedica esforços ponderáveis à conscientização de países amigos para os riscos de deixar-se a situação angolana à deriva. Esse trabalho continua na ordem do dia. Parceiros poderosos ainda hesitam em assumir um papel determinante na eliminação da pendência militar entre o Governo de Luanda e a UNITA de Jonas Savimbi. A síndrome da "fadiga com a África" contribui para confundir, na percepção do observador comum, as vicissitudes de Angola com as de tantos outros países africanos. O "fator CNN" passa ao largo dos problemas angolanos, talvez por não terem sido afetadas em maior medida as grandes empresas norte-americanas ou européias, que extraem petróleo off shore.

A ação diplomática brasileira baseia-se no diagnóstico de que o principal responsável pelo fracasso do Protocolo de Lusaka foi Savimbi. Cabe responsabilizálo por sua rebeldia. O Conselho de Segurança das Nações Unidas (CSNU) não pode mais deliberar sobre o assunto com base em uma premissa de eqüidistância entre as partes. Para preservar a própria autoridade do Conselho, é necessário manter a questão na ordem do dia e aumentar as pressões no sentido da plena implementação das sanções. A caracterização da UNITA como "movimento rebelde” abriu perspectivas de êxito para essa estratégia, reforçada, posteriormente, pelo endosso do CSNU ao relatório do Presidente do Conselho de Sanções, o Embaixador canadense Robert Fowler, que instou os Estados membros a tomar medidas adicionais para o aperfeiçoamento das sanções.

Recente estudo do Conselheiro Paulo Roberto Campos Tarrisse da Fontoura constata que as sanções do CSNU à UNITA se enquadram na nova tendência das Nações Unidas para limitar o alcance das punições a alvos precisos, de modo a minimizar impactos humanitários e efeitos sobre terceiros Estados. A Resolução 864 (1993) proíbe a exportação de armamento e material correlato, bem como de petróleo e produtos derivados à UNITA e a seus agentes. A de número 1127 (1997) veda a entrada e o trânsito de militares da UNITA e de seus familiares nos Estados membros, além de determinar o fechamento dos escritórios 
de representação do movimento rebelde no exterior e a imposição de um embargo de transporte aéreo e marítimo. A Resolução 1173 (1998) reprime a importação de diamantes procedentes de Angola que não tenham um certificado de origem emitido pelas autoridades governamentais angolanas, bem como o fornecimento de equipamentos e serviços de mineração. Determina, igualmente, o bloqueio dos fundos e recursos financeiros do movimento rebelde.

Essas sanções, aprovadas com o decidido apoio do Brasil, buscam identificar, estigmatizar e isolar a UNITA e suas lideranças, sem causar sofrimento desnecessário à população civil e sem impor ao Governo angolano amarras que inibam esforços em prol do desenvolvimento econômico e da superação dos problemas provocados pela guerra. Não obstante, durante a vigência dessas sanções, a UNITA adquiriu, por vias ilegais, armamentos em volume e qualidade capazes de sustentar um conflito prolongado, e tem mantido canais de contatos com o mundo exterior. Pondera Tarrisse que isso demonstra a necessidade de uma reflexão, por parte das Nações Unidas e particularmente do CSNU, sobre a estratégia em curso, com base na premissa de que a aprovação das Resoluções 864, 1127 e 1173 impõe aos Governos dos Estados membros o dever de empenharse para o estabelecimento de um regime capaz de funcionar na prática.

Não se pode ainda marcar data para o fim da crise angolana. Há, contudo, sinais de evolução positiva. O Presidente José Eduardo dos Santos convocou eleições para o próximo ano e se engajou em um programa de reforma econômica que já começa a apresentar resultados. Paralelamente, em uma demonstração de sensibilidade política, o Governo de Luanda se recompõe com as Nações Unidas e parece disposto a limar as arestas com os vizinhos regionais. Por sua vez, a empresa De Beers, gigante da mineração e comercialização de pedras preciosas, comprometeu-se a adquirir somente diamantes certificados pelo governo angolano. A pressão dirige-se agora a outros centros vendedores das gemas, acuados pela determinação do Embaixador Fowler de name and shame os violadores das sanções.

Angola readquire otimismo e esperança de que cesse enfim a intranqüilidade que susta há quatro décadas o desenvolvimento do país e corrói o bem estar do povo. As condições estão dadas para que o relacionamento bilateral receba notável impulso quando esse momento chegar. Projeções desse tipo começam a ser consideradas por setores do empresariado brasileiro, persuadidos de que chegou a hora de demarcar espaço no mercado angolano.

\section{A parceria nigeriana}

É tempo de conquistar posições também no mercado nigeriano. A Nigéria é o maior parceiro comercial do Brasil na África negra. Há dois anos, o fluxo nos dois sentidos atinge volume em torno de US\$ 1 bilhão, a despeito do relativo esfriamento das relações com o Brasil e com a maioria dos países ocidentais durante 
os quase cinco anos de governo do General Sani Abacha (novembro de 1993 a junho de 1998).

A eleição, no ano passado, do Presidente Olusegun Obasanjo, político habilidoso e conciliador, abre perspectivas de ampliação do relacionamento bilateral em múltiplos quadrantes. Obasanjo visitou o Brasil, ainda como Presidente-eleito, pouco antes de tomar posse, em maio de 1999. Foram então alinhavados os movimentos iniciais do processo de reaproximação, que contemplam, no corrente ano, a ida de missão comercial brasileira à Nigéria e a realização no Brasil de uma reunião multissetorial de alto nível.

Como se sabe, a sociedade nigeriana é particularmente complexa. Seus 120 milhões de habitantes dividem-se em pelo menos 250 etnias (entre as quais a dos iorubás, predominantes na região sudeste, os ibos, a leste e os hausas e fulanis, ao norte) e religiões (50\% islâmicos, 35\% católicos, 15\% animistas). As tensões regionais, recorrentes desde a independência, alcançada em 1960, levaram os ibos a proclamar a "República Independente de Biafra", seguindo-se a guerra civil, de 1967 a 1969. Desde então, sucedem-se os golpes militares.

A Nigéria é, por outro lado, um país com uma elite refinada, uma diplomacia atuante e um exército bem treinado e equipado. Foi instrumental na criação, em 1975, da "Comunidade Econômica dos Estados da África Ocidental (CEDEAO ou, em inglês, ECOWAS, como prefere a nossa imprensa). Exerce notória ascendência sobre o entorno africano, haja vista a derrota diplomática imposta a Mandela, que advogou, sem nenhum sucesso, a imposição de sanções da OUA ao governo Abacha, na seqüência da execução do escritor Ken Saro-Wiwa e outros oito líderes da minoria ogoni, em novembro de 1995. Na esteira desse episódio, realizamos consultas com os vizinhos da Nigéria. Estes, temerosos das consequiências políticas, econômicas e militares de um isolamento da Nigéria, sem exceção recomendaram que mantivéssemos a Embaixada em Lagos em pleno funcionamento, ao invés de fechá-la em sinal de protesto, como preferiam os integrantes da Commonwealth.

Os desmandos de Abacha incentivaram a corrupção e o narcotráfico. Foi nesse contexto que a VARIG suspendeu o vôo Rio de Janeiro - Lagos. Também aumentaram consideravelmente, desde essa época, os casos de "fraude 419", praticadas por falsos empresários que oferecem, por meios de cartas ou correio eletrônico, vantagens mirabolantes a empresários estrangeiros gananciosos e mal informados (419 é o número do artigo do Código Penal nigeriano que tipifica o delito). Fica o alerta.

A cultura nigeriana mereceu sempre a atenção de centros afro-brasileiros; existe projeto de ensino do idioma iorubá em algumas de nossas universidades e, recentemente, o Governo da Bahia concedeu espaço para a instalação, no Pelourinho, de uma Casa da Cultura da Nigéria. Em 1998, a Braspetro assinou dois contratos de risco para a prospecção de petróleo no delta do Níger; em breve, 
a empresa deverá instalar escritório local e intensificar sua presença em território nigeriano. Os entendimentos político-diplomáticos também prosperam e prevê-se para breve a realização de uma reunião multissetorial de alto nível, seguida de visita ao Brasil do Vice-Presidente Alhaji Abubakar.

A natural atração exercida pela África do Sul, Angola e Nigéria não exclui a cooperação com outros países, em geral assentada sobre um projeto-âncora ou uma idéia-força. Entre esses, incluem-se o Cameroun, país em que a AndradeGutierrez mantém empreendimento promissor; o Gabão, onde poderá ser instalada uma mini-siderúrgica pela ISCOM; Gana, que se tem distinguido no interior da CEDEAO pelo equilíbrio da atuação diplomática e pelo estímulo à integração econômica; o Congo Brazzaville e a Guiné Equatorial, com os quais a Braspetro desenvolve negociações; o Mali, alvo de atenções do Banco Mundial e para o qual a CODEVASF desenhou interessante projeto; a Namíbia, que oferece condições excepcionais para a entrada de produtos brasileiros em território africano e com a qual a Marinha do Brasil mantém exemplar cooperação. E, evidentemente, não pode faltar nessa lista uma especial menção aos países lusófonos, nossos sócios na edificação da Comunidade dos Países de Língua Portuguesa - CPLP.

\section{A CPLP}

A comunidade tem raízes na imaginação criadora de pensadores da estirpe de Silvio Romero e Gilberto Freyre. A base de sua arquitetura foi construída pelo Presidente José Sarney, ao criar o Instituto Internacional de Língua Portuguesa IILP, em 1989. Mas seu maior entusiasta foi, sem dúvida, o Embaixador José Aparecido de Oliveira, que impeliu o movimento cuja institucionalização só se verificaria, entretanto, sob o Governo Fernando Henrique Cardoso.

Da gênese se infere uma primeira dificuldade para a gerência do projeto. Entre a concepção e a criação, lembra Eliot, há sempre sombras. Os sonhadores encontram sempre defeitos na versão possível do sonho para a realidade.

Os Chefes de Estado e de Governo de Angola, Brasil, Cabo Verde, Guiné Bissau, Moçambique, Portugal e São Tomé e Príncipe, reunidos na Conferência de Lisboa de julho de 1996, convieram na criação de um mecanismo com três funções básicas: a concertação político-diplomática, a valorização da língua portuguesa e a cooperação técnica, científica e tecnológica. Para tanto, acordaram encontrar-se a cada dois anos em reuniões de cúpula, de onde partiriam as diretrizes gerais para a atuação do organismo e determinaram que seus Chanceleres conferenciariam anualmente, para imprimir os rumos do Comitê de Concertação Permanente CCP, formado pelos Embaixadores dos sete países membros em Lisboa, e do Secretariado-Executivo (também sediado, provisoriamente, em Lisboa).

Como órgão de concertação político-diplomática, a CPLP teve seu batismo de fogo em 1998, na crise da Guiné Bissau. Ao negociar o fim das hostilidades 
entre as partes em conflito, ao articular-se com a CEDEAO, órgão regional com evidentes responsabilidades no caso e, sobretudo, ao evitar a repartição do território guineense, sem violência e sem a militarização de seus métodos, a CPLP passou com louvor no teste, conforme reconheceram, entre outros, o Secretário-Geral da ONU e os governos dos EUA e da França.

O fenômeno já foi constatado: a globalização está levando países em todo o mundo a desenvolverem uma consciência mais aguda de sua individualidade. Sendo a língua portuguesa o traço de união que confere identidade aos membros da CPLP, é natural que a Comunidade se dedique a valorizá-la e difundi-la. A implementação do IILP e do Acordo Ortográfico são etapas cruciais dessa tarefa.

Das três vertentes da CPLP, a cooperação técnica é, talvez, a mais premente para a maioria dos membros africanos. O Brasil vem se empenhando para garantir uma base operacional adequada à cooperação intracomunitária. Já foi assinado um Acordo Geral, definindo regras comuns a todos, negociado um Fundo Especial, ou seja, um "trust fund” vinculado a projetos específicos, e estabelecida a área prioritária de ação, que é a da educação e formação profissional.

Um aspecto saudável a ressaltar é o expressivo número de iniciativas que vêm sendo tomadas, espontaneamente, com vistas à cooperação nos mais variados setores. A CPLP não é um arranjo exclusivista entre chancelarias. Para ser efetiva, deve empolgar todas as áreas dos governos e das sociedades dos países membros. São, assim, bem-vindas as múltiplas iniciativas em curso congregando Tribunais de Contas, Ministérios da Agricultura, Educação, Meio Ambiente, Justiça, Telecomunicações, Trabalho, e ainda dos Correios, organizações cooperativistas, entidades municipais, juristas, jornalistas, associações empresariais, estudantis, assistenciais — e a lista não é exaustiva. As resoluções emanadas desses encontros agregam substância à pauta da CPLP.

Tendo em vista que o Brasil havia sido o impulsionador da idéia comunitária, julgou-se, em alguns círculos, que o primeiro Secretário Executivo deveria ser um brasileiro. Mas o tempo vai demonstrando que foi sábia a opção pelo preenchimento do cargo por um critério neutro de ordem alfabética. Dadas as características da Comunidade, composta por seis antigas colônias, cinco das quais africanas e uma ex-potência colonial, nada mais natural do que confiar a tarefa a um africano. Além disso, a circunstância de Marcolino Moco ter sido Primeiro Ministro angolano é expressiva. Uma Angola pacificada e atuante será um fator de fortalecimento da CPLP.

Em julho próximo, chegará a vez de um brasileiro assumir a chefia do Secretariado Executivo. Encontrará um arcabouço normativo bastante avançado, prioridades de ação definidas e mesmo uma razoável base financeira com que trabalhar, mercê de recursos recém-aprovados pelo Congresso Nacional. Deverá dedicar-se à divulgação das metas da CPLP, dar organicidade às várias iniciativas 
que se desenvolvem sob o guarda-chuva comunitário, ampliar o diálogo com organismos internacionais e associá-los a projetos conjuntos, a fim de maximizar a eficácia dos recursos escassos. Precisará de sensibilidade para lidar com as conseqüências do desequilíbrio entre as exigências da opinião pública em Portugal, onde os assuntos dos países lusófonos fazem manchetes todo dia, e o silêncio no Brasil, onde a mídia não tem intimidade com as questões comunitárias. E será convocado a desempenhar um papel político de crescente importância, pois a CPLP já tem maturidade bastante para pronunciar-se sobre temas como democracia e direitos humanos.

A CPLP não é o remédio para todos os males. Trata-se de um instrumento político-diplomático, destinado a promover a aproximação entre os seus membros e forjar parcerias. Não substitui, mas sim complementa e fortalece a ação bilateral. Seus objetivos são de longo prazo, suas regras democráticas, seu espaço aberto à colaboração de outros parceiros, públicos ou privados, intra e extrazona. Está dando certo na medida em que vem se firmando sem precipitações, não se transformou em "chasse gardée” de nenhum país, nem em caixa de ressonância para reivindicações dos mais carentes, nem em mais uma burocracia amarrada a projetos paroquiais. Para prosseguir no caminho correto, deverá ater-se a metas exeqüíveis, maximizar a equação custo/benefício e, sobretudo, consolidar consensos. Dessa maneira, servirá cada vez melhor aos seus sete integrantes - oito, muito em breve, quando se der a plena incorporação de Timor Leste.

\section{A necessária ação multilateral}

Ao considerar as questões da África, convém manter em mente a observação de Abedaio Adedeji de que um processo de alteração profunda e durável no panorama africano deve ser informado por uma concepção política abrangente.

O estancamento das crises que persistem em várias regiões africanas é o tipo de missão capaz de conceder um renovado destaque às Nações Unidas, organização que dispõe da amplitude de ação necessária à abordagem integrada dos problemas no continente. No entanto, as decisões no âmbito da ONU refletem o que pensam, ou pelo menos aquilo a que não objetam os países mais poderosos. Na interação entre as múltiplas soberanias, anotou Celso Lafer, a anarquia dos significados é freqüentemente equacionada com base na visão dos mais fortes, embora haja espaço para acomodações, uma vez que mesmo os membros permanentes do CSNU sentem-se compelidos a se legitimarem, balizando-se pelos princípios éticos da Carta de São Francisco.

Realisticamente, as Nações Unidas pouco avançarão, se além do empenho dos próprios africanos não houver o comprometimento das principais potências 
com a construção de um futuro melhor para a África. Por isso, é digna de nota a movimentação em curso na Europa e nos EUA nesse particular.

A Cúpula Euro-Africana, realizada no Cairo, em abril do corrente ano, reuniu 52 países africanos e 15 europeus em torno de uma agenda negociada exaustivamente, na qual a questão da dívida africana, hoje avaliada em US\$ 350 bilhões, recebeu atenção especial. Acordou-se destinar um bilhão de euros ao Fundo de Desenvolvimento Europeu para reduzir os efeitos do endividamento sobre os HIPCs. França e Alemanha foram além e anunciaram o cancelamento parcial dos débitos dos países africanos mais pobres. No balanço final dos trabalhos, constatou-se que, de lado a lado, existe hoje uma consciência mais objetiva dos pecados e limites individuais. Há também uma preocupação crescente com a objetividade.

Nos EUA, após a viagem do Presidente Bill Clinton, no primeiro semestre de 1998, a seis países africanos, parece estar em andamento uma significativa inflexão política. Em março do ano passado, a US-Africa Ministerial Conference: Partnership for the XXI Century juntou em Washington representantes de 46 países subsaáricos, que ouviram do próprio Presidente Clinton promessas de empenho na redução da dívida dos países mais pobres. Embora não responda às expectativas empresariais africanas, o African Growth and Opportunity Act no mínimo indicará, se aprovado pelo Senado norte-americano em setembro próximo, um renovado interesse da classe política dos EUA no encaminhamento das questões africanas.

Uma bem avisada participação dos países mais ricos seria essencial na canalização de recursos para investimentos destinados a ampliar e modernizar os sistemas produtivos em países africanos. Investimentos com seguro e condições de pagamento adequados são necessários para assegurar os aperfeiçoamentos da infra-estrutura e o estímulo à eficiência em setores chave da economia africana. Além de eficazes, investimentos dessa natureza são democráticos e têm potencial mais duradouro do que programas assistenciais.

A questão do acesso ao crédito assume, igualmente, papel estratégico na ruptura do círculo vicioso da falta de investimentos - redução da eficiência riscos ampliados - dificuldade de obtenção de créditos para investimentos.

O aperfeiçoamento dos recursos humanos é fator que reclama atenção especial. Neste ponto, é necessário não estimular “evasão de cérebros” nem gerar “reservas de mercado” para profissionais dos próprios países doadores. A cooperação atrelada a contrapartidas do interesse de empresas dos países doadores já demonstrou sua insuficiência como motor de desenvolvimento. Seria ainda aconselhável arquitetar iniciativas tri ou multilaterais, estimulando, nos projetos entre doadores desenvolvidos e recipiendários africanos, a participação de outros países, como o Brasil, sem recursos, no curto prazo, para investimentos na África, porém capacitados humana e tecnicamente a prestar assistência. 
Os processos de integração política e econômica merecem incentivos. Processos dessa natureza contribuem para a diminuição das divergências interétnicas e, além de ampliar a escala, fomentam a estabilidade dos mercados.

A organização de eventos de alcance internacional direcionados à divulgação dos aspectos positivos e das potencialidades africanas nos âmbitos cultural e artístico seria igualmente oportuna para a melhoria da imagem (e da auto-imagem) do continente.

Na viabilização dessas medidas, um elemento relevante há de ser o estímulo a ações de caráter positivo, ao invés do recurso ao big stick ou a ameaças de punição. Será mais produtivo contribuir para o aperfeiçoamento das forças policiais e judiciárias dos países africanos do que votar resoluções de condenação por desrespeito aos direitos humanos; apoiar governos engajados em programas políticos construtivos, ao invés de aplicar seletividade somente na pressão sobre rogue countries.

\section{Conclusão}

Os três paradigmas clássicos da convivência internacional sistematizados por Martin Wight oferecem moldura conceitual utilíssima para a compreensão da problemática africana e da posição brasileira diante dela. O realismo do poder, preconizado por Maquiavel e Hobbes, marca presença no cenário africano desde o Congresso de Berlim e se infiltra no abandono subliminarmente autorizado pela noção de failed states. O potencial de sociabilidade que torna possível, no modelo de Grócio, conceber a política internacional como um cenário de entendimentos mutuamente proveitosos e não como um jogo de soma zero, vem orientando tentativas de aproximação, da catequese missionária aos esquemas de cooperação europeus. Neste fim de século, abrem-se enfim as portas para que as relações do mundo com a África rejam-se também por uma "razão abrangente”, na tradição kantiana.

Como já observou Rubens Ricupero, a política externa se desenvolve em um mundo áspero e é nessa arena que precisamos operar a nossa inserção — não a inserção ideal, que requereria um mundo ideal e um país ideal, mas a necessária, a resultar do ponto de interseção entre as oportunidades e as limitações do sistema internacional e do próprio Brasil.

Não dispondo de excedentes de poder, como lembrava Saraiva Guerreiro, o Brasil não poderia interagir com o sistema internacional a partir de fórmulas de imposição da força. Assim, em nossas relações com a África, desde os anos 70 preferimos explorar o potencial de racionalidade e desenvolver os interesses recíprocos. Hoje, em uma época histórica em que o mercado tornou-se o remédio internacionalmente receitado para os males do desenvolvimento, permanece legítimo e adequado que a política externa brasileira sublinhe a dinâmica grociana e destaque 
a premência da ampliação do comércio, as potencialidades de certas parcerias e a dinâmica da cooperação. Atrelada no cotidiano ao possível, a nossa ação diplomática não deixa, porém, de se bater nos foros pertinentes para a desejável convergência de atenção e recursos necessários à superação dos problemas econômicos e sociais africanos.

A solidariedade não foi, entretanto, a palavra de ordem dos anos 90. A lógica da cooperação, que se presumiria reforçada em uma era de globalização, vem sendo corroída por impulsos de fragmentação nas mais variadas latitudes. Pelo menos na fase atual, que se supõe transitória, o império do livre mercado aguça desequilíbrios, ao desacreditar mecanismos de correção, como a ajuda externa, reduzida a níveis sem paralelo com aqueles aplicados durante décadas aos países africanos. Em conseqüência, ao invés de integração, vê-se multiplicarem-se os focos de tensão em Angola, Eritréia, Etiópia, Libéria, República Democrática do Congo, Serra Leoa, Somália, Zimbabue, em uma lista de “a” a "z” que a mídia parece aumentar todo dia.

Percebem-se, porém, sinais de crescente mobilização da comunidade internacional em favor de um resgate da África. Esses sinais provêm sobretudo dos EUA e da Europa. Isso pode sugerir motivações maquiavélicas, mas como a realidade tende sempre a agregar ingredientes grocianos e kantianos ao realismo do poder, e tendo ainda em vista que os impulsos gerados pelos grandes centros em geral têm fôlego para contagiar o resto do mundo, é de supor que estejamos em vias de presenciar um novo movimento internacional em favor do desenvolvimento econômico-social, da democracia, dos direitos humanos e da efetiva paz na África.

O foro por excelência para a legitimação dos ideais grocianos e kantianos, relembra Celso Lafer, é a Organização das Nações Unidas. Na avaliação de prós e contras e na proposição de soluções viáveis para os problemas da África, as Nações Unidas estão sendo chamadas a desempenhar mais uma vez um papel de relevância, seja para as nações africanas, seja para a credibilidade da própria Organização. Essa tendência se encaixa perfeitamente com as preferências do Brasil, que tem a experiência, a sensibilidade, as condições materiais e o interesse em dar uma contribuição efetiva a essa tarefa, decerto um dos grandes desafios que a comunidade internacional terá de enfrentar nesse início de século.

Em paz e democratizada, com regras do jogo estáveis e previsíveis, a África potencializará oportunidades para o Brasil, pela facilidade de nosso diálogo com várias nações africanas, por nossa capacidade técnico-científico-tecnológica em escala com as carências continentais, pela afinidade de experiências históricas. Somos percebidos por muitos de nossos vizinhos da outra margem do Atlântico como um modelo, encarado com estimulante simpatia pela maioria dos 53 países subsaáricos - eis aí um considerável capital diplomático em debates e votações nos foros mundiais. A comunidade internacional aprecia o nosso trânsito diplomático com os parceiros africanos e nossa capacidade para forjar consensos dinâmicos 
entre os países mais ricos e os mais pobres. A solidariedade para com a África se apresenta, nesse contexto, como um objetivo insubstituível, que agrega valor e substância à política externa do Brasil.

Maio de 2000

Resumo

Distinguindo as percepções mais difundidas sobre as relações do Brasil com o continente africano, o artigo avalia as ênfases diplomáticas brasileiras nos planos bilateral e multilateral. A tendência atual seria de uma crescente mobilização em favor de um resgate da África que se realizaria por meio da Organização das Nações Unidas. Essa tendência seria a mais adequada para as preferências do Brasil.

\section{Abstract}

Contrasting the most known perceptions about relations between Brazil and Africa, the article evaluates Brazilian diplomatic emphasis on bilateral and multilateral levels. There would be a trend towards growing mobilization in favor of a rescue of Africa that would be carried out through United Nations. This trend would fit Brazilian preferences.

Palavras-chave: Brasil. África. Política externa. Diplomacia brasileira. Key-words: Brazil. Africa. Foreign policy. Brazilian diplomacy. 